\title{
Meet the Editors of an Outstanding Journal - An interview
}

\author{
Andrea Pfeifer
}

Published online: 30 November 2011

(C) Springer-Verlag 2011

Who are the Editors of Analytical and Bioanalytical Chemistry? Who turned a number of small Europe-based analytical journals into an outstanding success story - the internationally renowned journal named Analytical and Bioanalytical Chemistry (ABC)?

$A B C$ is published under the leadership of a team of nine eminent analytical scientists from all parts of the world: Sylvia Daunert, Miami, FL, USA; Philippe Garrigues, Bordeaux, France; Günter Gauglitz, Tübingen, Germany; Klaus G. Heumann, Mainz, Germany; Kiyokatsu Jinno, Toyohashi, Japan; Aldo Roda, Bologna, Italy; Alfredo Sanz-Medel, Oviedo, Spain; Stephen A. Wise, Gaithersburg, MD, USA; and Regional Editor Central Europe Maciej Jarosz, Warsaw, Poland. They talk about research and motivations, about themselves, and their dreams for ABC to Andrea Pfeifer. We invite you, our readers, to meet these nine Editors.

Each of you is an established and renowned scientist, and as a group you cover almost the full range of research featured in $\mathrm{ABC}$. Please describe your own research and your motivation. Where did you start from and where do you see your field headed?

SYLVIA DAUNERT: Since childhood I have turned to nature for inspiration. Learning from natural phenomena, how living beings function on the nanoscale, enables us to create bioinspired nanotechnology and nanodevices that cannot be produced by using man-made technology alone. My current research interests are in bionanotechnology at the interface between analytical biochemistry, molecular biology, and bioengineering, e.g. use of recombinant DNA technology to design new molecular diagnostic tools and biosensors based on genetically engineered proteins and cells for biomedical,

\section{A. Pfeifer $(\bowtie)$}

Analytical and Bioanalytical Chemistry, Springer,

Tiergartenstr. 17,

69121 Heidelberg, Germany

e-mail: abc@springer.com environmental, and pharmaceutical applications. If I had to explain this to a child, I would say, "We look into nature and we try to copy what nature does so we can make new devices that can measure the amounts of important compounds in the body and in the environment." Bionanotechnology is just in its inception. I view the field exploding as we gain knowledge from events and processes that occur in nature. These will then provide an inspiration to create or adapt tools that can be used in such varied applications as energy sustainability, environmental analysis and remediation, biomaterials, biomedical sensing, imaging, drug delivery, and a host of therapeutic devices.

MACIEJ JAROSZ: Many years ago I began looking for sensitive spectrophotometric methods for determination of trace amounts of elements. Today my research focuses on hyphenated techniques applied to identification of the colorants in historical art works, on examination of mechanisms of transportation of metalodrugs in the bloodstream, and on food speciation analysis. Or, in simpler words, finding responses to questions such as "Why is your skirt blue? What happened to the pill you have taken for your stomach ache? Why do strawberries taste sweet?" My plans for the future? I would love to spend the next ten years in my laboratory - and still enjoy it!

ALDO RODA: The focus of my current research is the development of ultrasensitive bioluminescence and chemiluminescence analytical methods and chromatographic methods coupled with mass spectrometry and their application to biomedical, agro-food, and environmental analysis. One of the principal purposes of these studies is to transfer the developed methods outside the research laboratory, e.g., for use in routine clinical analysis or environmental monitoring. In simple words, my research deals with the development of small devices designed to improve the general quality of life.

My plans are to continue managing my laboratory and my co-workers, because I still have new ideas! I also plan to continue my activities within the Italian Chemical Society, with 
the objectives of improving the overall quality of our scientific work and promoting young scientists.

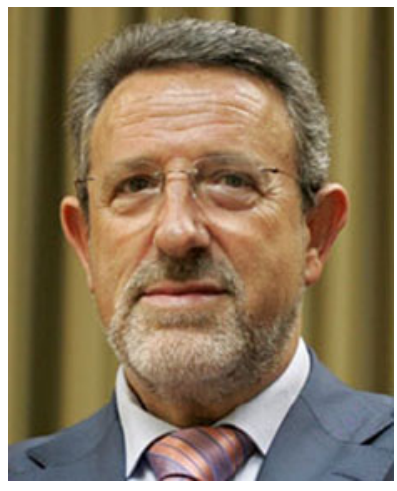

ALFREDO SANZ-MEDEL: For many years my research activities mainly focused on atomic spectrometry. However, elemental information alone is insufficient to solve many current scientific problems. Accordingly, my research concentrates on the development of new mass spectrometry tools capable of collecting elemental and molecular information simultaneously and in only one instrument, and on the application of plasma-MS instruments to solve real-life problems in collaboration with professionals from other fields (physicists, biologists, clinical researchers, and engineers).

Chemistry is mainly about compounds or chemical species. Nowadays there is a clear trend in using chemistry to solve problems in neighboring fields, for example environmental science, biochemistry, biology, or medicine. I believe that today this "elemental-only" field is heading toward "integration" of older atomic spectrometry concepts, techniques, and strategies into the "whole chemistry" (molecules) and "whole physics" (e.g. nanoparticles) challenges of current science. This trend is very powerful and I think that the very specific questions asked in these areas will show a need to "revitalize" atomic spectrometry.

After having developed analytical tools for atoms, isotopes, and molecules, we are now starting to build up a powerful infrastructure to characterize nanoparticles (e.g. field-flow fractionation-MALMS-UV and ICP-MS detectors equipped on-line), to work on quantum dots (QDs), to develop multiplex protein determinations (by resorting to appropriate antibodies), and to collaborate with medical doctors and biologists to study QDs toxicologically and to use those NPs, with plasma-MS based techniques, for nanomedicine applications (e.g. genomic and proteomic quantitative studies of glaucoma and aged-related diseases).

GUENTER GAUGLITZ: If I had to explain my research field to, e.g., a child, I would refer to soap bubbles in the sun - it is possible to see brilliant colors, and these colors change when the bubbles expand. This means their skin's thickness changes. It is such a change we use in a thin layer by implanting molecules or adsorbing molecules in order to determine the amounts of molecules.

I started my research career in photochemistry and photokinetics, using spectroscopy to monitor changes in concentrations. Spectroscopy is rather closely related to my current field of optical detection in sensing.
However, the approach is really different. Today, my group and I work on bio- and chemosensing. In particular, we want to find biosensors for process control in biofermentation, in clinical diagnostics, especially in POCT (point of care testing), and food analysis. In the future I expect sensing to become increasingly interesting, supporting classical analysis and, in some cases, reaching new frontiers.

PHILIPPE GARRIGUES: My main research interests focus on the REACH (registration, evaluation, authorization, and restriction of chemical substances) regulation. Apart from the implications of the REACH regulations for analytical chemistry itself, to achieve the optimum implementation of REACH there is a need to collaborate with experts from Law and the Social Sciences to achieve better understanding of the different needs of those in other disciplines. Another aspect of my research is life cycle assessment applied to the design of new materials (for example intelligent polymers, nanomachines). To anticipate further environmental and sanitary problems of chemicals if used and released in the environment, we need to develop active research for a better understanding of the fate of chemicals. And the future of environmental analysis? Chemical characterization is, nowadays, much more toxicity-driven, and chemicals are characterized on the basis of their biological effects: endocrine, carcinogenic, mutagenic, neurotoxic, etc.

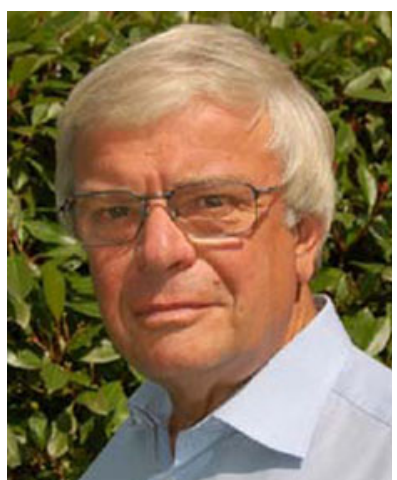

KLAUS HEUMANN: The focus of my research is trace and elemental species analysis. If I had to explain this to a child, I would described it as trying to make visible very small amounts of substances which cannot be seen by us. I started by analyzing radionuclides. This introduced me automatically to trace element analysis. The most recent knowledge that not only the concentration of an element but much more its chemical form strongly affects the toxicity, bioavailability, and mobility in the environment of this substance brought me to elemental speciation.

Species-unspecific isotope-dilution ICP-MS in combination with hyphenated techniques is today's most important and accurate method of quantification in metallomics and of sulfur-containing proteins.

STEVE WISE: My education and training were in analytical chemistry with emphasis on chromatography, particularly liquid chromatography. My early laboratory 
work, and the current efforts of the analytical chemists in my organization, is focused on the establishment and implementation of different chromatographic methods for use in the development of reference materials. A primary focus of our analytical chemistry-related research is to improve the quality of chemical measurements. One aspect of this work is to develop reference measurement procedures and reference materials for use by the chemical measurement communities.

KIYOKATSU JINNO: During my graduate research my scientific focus was on radioactivation analysis. After five years in industry, for the past 30 years, since joining the faculty of Toyohashi University of Technology, I have been working in separation sciences, e.g. for environmental and clinical applications. A common dilemma in environmental analysis is the pollution of our environment as a result of the use of large amounts of energy and chemicals to determine the extent of its pollution. Motivated by the trend of "Green Chemistry", in the past decade my research has focused on the miniaturization of sample preparation processes, with the objective of reducing both solvent and energy consumption. In clinical analysis, serious diseases should be diagnosed by sampling a drop of blood and/or by sampling breath with a miniaturized device. The advantage is that breath analysis, especially, does not involve additional pain for patients who are already in pain from the disease.

Currently, being Vice-President at my university seems to involve too many administrative duties. But for my retirement my plan is to remain active as a scientist, e.g. by teaching and taking up my research, maybe in Asian countries.

In your research, you have surely met some obstacles. What was the trickiest problem you have had to overcome? How did you solve it? What made you persevere? Have there been sources of inspiration, e.g. a specific incident or discovery? And, in your opinion, which (recent) discovery might prove most valuable to your field of (bio)analytical research or beyond?

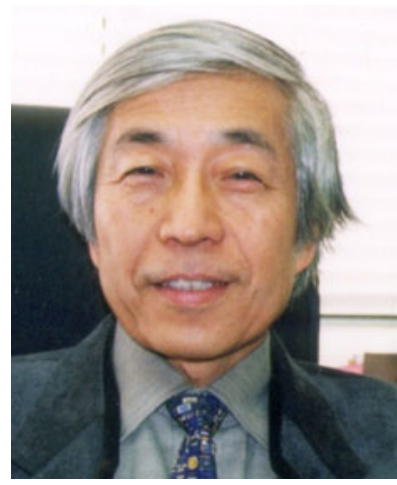

KIYOKATSU JINNO: Inspired by San Francisco's “Golden Gate Bridge", a suspension bridge supported by cables containing over 25,000 separate metal wires in bundle-like structures, we developed a fiberpacked capillary device for extraction and pre-concentration in sample preparation processes, using bundles of polymer fibers with micrometer diameters. To pack the bundle of fibers proved a tricky process. In sample preparation processes surely the solid-phase microextraction technique of Janusz Pawliszyn (Canada) is the most exciting recent discovery. Showing that such tiny devices can be useful for extraction and preconcentration led to the field of miniaturization and has inspired researchers in this field to numerous subsequent discoveries.

PHILIPPE GARRIGUES: Specific incidents that "fired up" my field, environmental chemistry? The backlog of information from recent great technological disasters (Deep Water Horizon Oil Spill in 2010, Fukushima Nuclear explosion in 2011) are "important" in terms of the extent of environmental damage, the related dispersion of chemicals, and very valuable experience in remediation.

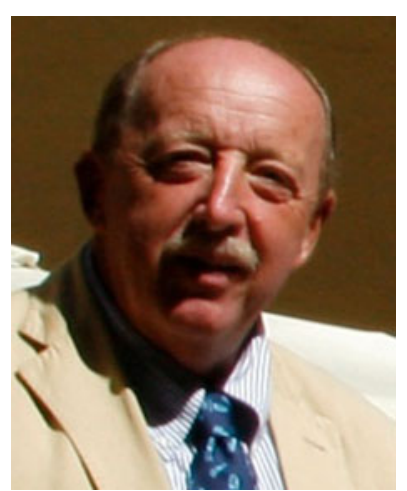

ALDO RODA: Most inspiring to me was a scholarly stay at UCSD in 1981. At that time research on the campus was highly active and very stimulating, and I had the chance to work with famous scientists, including Marlene De Luca. On the basis of her husband Bill Mc Elroy's discovery of the firefly light emission mechanism she introduced the luciferase gene into a tobacco plant which became luminescent. This discovery led to very important research activity in bioluminescence and reporter gene technology. At that time I worked at least 12 hours a day, seven days a week. In retrospect this was the most exciting and scientifically productive period of my career as a researcher.

SYLVIA DAUNERT: Mimicking nature in the laboratory is tricky and sometimes challenging. One must have a multidisciplinary broad approach to tackle those challenges and use a variety of strategies that range from rational design to random methods across scientific boundaries. But most inspiring to me was a private tragedy. My oldest daughter was diagnosed with Crohn's disease when she was thirteen years old, and witnessing how this debilitating and painful disease affected children, and, in particular, my own child, motivated me to find a better means to manage this disease. This spurred collaboration with her physicians, eventually resulting in the development of biosensors for detection of biomarkers in saliva that patients could ultimately use to monitor their health status on a daily basis with the ultimate objective of improving the quality of life of Crohn's patients - including that of my daughter. 
When I started thinking about how to take advantage of the bioluminescence of organisms present in nature to develop highly sensitive diagnostics and imaging technology, maybe some twenty years ago, I could not have foreseen that one day we would be able to manipulate the genetic code of photoproteins and tailor their bioluminescence properties by incorporating unnatural amino acids beyond the 20 canonical amino acids found in nature. The potential applications of these extremely sensitive bioluminescence proteins are abundant and rival those of their partner fluorescent protein, green fluorescent protein, GFP, which revolutionized reporter gene technology and molecular imaging in the last decade of the 20th century.

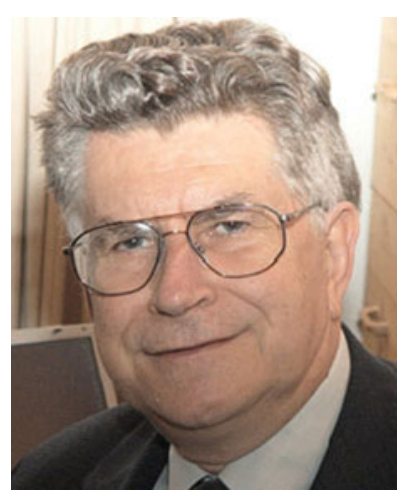

GUENTER GAUGLITZ: In the beginning, working with sensor arrays and becoming familiar with chemometrics, a field I had not worked in before, proved very challenging, and many tricky problems arose which had to be solved. Most valuable to my work was the discovery how to measure agonist and antagonist interactions with receptors using reflectometric interference spectroscopy. This enables not only measurement of interactions but also understanding of effect-based analysis (closely related effects). Accordingly, the discovery of the pressure dependence of the refractive index was very inspiring to my research.

STEVE WISE: I see the development and improvement of liquid chromatography-tandem mass spectrometry (LCMS-MS) instrumentation during the last decade as one of the most significant "discoveries" that is affecting analytical and bioanalytical chemistry, and will continue to affect it for years to come.

MACIEJ JAROSZ: The trickiest problem I had to overcome was the coupling of capillary electrophoresis to ICP-MS. Fortunately, I have really talented coworkers!

Some more personal questions: Whom do you admire the most and why? And in your career, what was the best/worst advice you ever received? What is your advice for young analytical scientists today?

ALDO RODA: I still admire my teacher from my time at UCSD, Professor Alan Hofmann. He is now almost 82 years old but still active and scientifically up-to-date. I correspond with him often, and once a year I visit him and discuss scientific topics. To me he is a role model of a scientist and Maestro!

The best advice I received was always to stay updated on my research activity and learn from highly respected scientists. My advice to the young generation of scientists - to achieve a solid scientific background, to remain highly motivated and curious, considering research the "best job" and, maybe, the only "hobby".

GUENTER GAUGLITZ: Those persons who do not despair even in the most difficult circumstances, but just go on, have my full respect.

The best thing that happened to my career was not the advice of a colleague, but something a competitor said, telling me to do sensing, a field he thought I would NOT be very successful in ... My advice to young people - do not focus on a small field, but get a broad view - this is most necessary in analysis! Persevere, and do not let setbacks get you down.

KLAUS HEUMANN: I especially admire Otto Hahn for his excellent and precise analytical intuition, which enabled him to discover the nuclear fission of uranium, and how he handled all the corresponding problems with this discovery. In addition, I loved his delicate humor which I witnessed during a Nobel Prize Winner Meeting with students.

The best advice is to stay focused on a research field in which you understand all the fundamental principles. And something I learned too late during my career as a researcher-present very recent results, e.g. at conferences or seminars, but do not reveal too much too soon. My advice to the next generation-never give up even if the results are not successful in the beginning as long as you know that the problem can be solved.

KIYOKATSU JINNO: The best advice I was given in my life was from Professor Sasaki, one of the pioneers in chemometric research in analytical chemistry. His words were "If you have found any new things in your research works, you need to publish it as soon as possible because it is a common sense that human beings can find similar things at a similar time. Publishing the findings is the most important step to mark your existence in your research fields. A tiny thing will make a huge success with the time being".

Networking is my suggestion to the young generation of researchers. When attending symposia and conferences we need to make contacts, friends even, and establish collaborations. But what is more, relationships are so important because we are, first, human beings before being scientists.

MACIEJ JAROSZ: The person I admire the most is my wife- "why" is obvious!

The best advice I ever received - to be self-reliant. And my advice for young researchers: take great care when planning 
their research and writing up papers from these conclusions to avoid/minimize wasting time.

PHILIPPE GARRIGUES: The best advice I received, and would like to share is:

1. follow the procedure, and

2. get off the beaten track.

You will be at your own in the beginning, but then in the future you will be seen as a pioneer in the field.

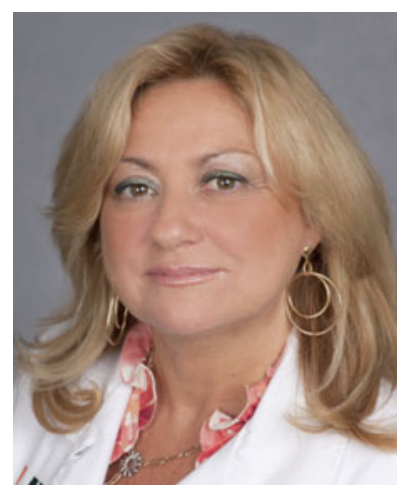

SYLVIA DAUNERT: As a scientist I admire the imagination and talent of Leonardo da Vinci. He was "the" Renaissance Man, unparalleled in his imagination and foresight into the future. His variety of talents is still incredible: engineering machines, painting, and studying anatomy in detail, to name just a few. I wish he lived today because with his lateral thinking his contributions to science and technology would prove revolutionary-how fantastic!

Perhaps the worst advice I received was that I should focus my research on one particular field only, narrow the scope of my work, and avoid collaborating with others. That is totally against my philosophy, both personal and in research. I firmly believe that science benefits greatly from collaborative efforts among investigators from different fields.

To successfully tackle modern scientific problems, young scientists need to acquire the following traits:

1. be creative, open minded, and able to assess problems with a multidisciplinary approach;

2. build, employ, and understand instruments;

3. perform selective, sensitive, accurate, and reproducible measurements;

4. interpret data;

5. be a critical thinker; and

6. communicate and share findings within the global environment.

This brings me to my future plans. I would like to continue promoting the importance of interdisciplinary research by advancing discovery and creating new initiatives that will result in emerging technologies that can reach beyond the academic environment. This can be accomplished by:

1. educating the new generation of physician scientists and Ph.D.s by exposing them to interdisciplinary and discovery science in their coursework and provide them with research opportunities;
2. promoting global multidisciplinary science; and

3. emphasizing the transfer of discoveries and emerging biomedical technology to the public sector.

And a more private question: What do you enjoy most when you have time to spare?

SYLVIA DAUNERT: There is so much I love to dotraveling, swimming, sports in general, cooking and entertainment, reading, enjoying movies, and, last but not least, spending time with my children.

ALDO RODA: I enjoy reading scientific papers, books, and, recently, playing golf.

KIYOKATSU JINNO: I enjoy listening to classical music, especially Bach, and reading car magazines. I like cars and have had a variety of different cars made by Subaru, Nissan, Toyota, Peugeot, BMW, Saab, and Volvo. I very much enjoy the differences.

GUENTER GAUGLITZ: Model railroad, hiking, camping, and filming.

MACIEJ JAROSZ: I love to spend my rare spare time in our cottage, but I also go on long journeys whenever possible.

KLAUS HEUMANN: To me, there is an unsatisfied curiosity to learn and see more about foreign countries and cultures, hopefully until the end of my life. For recreation I love to play golf (but not very successfully) and biking, especially in winegrowing areas, but also to further participate in future developments in analytical chemistry. My plans for the future? To do everything to enjoy my life without health problems.

As Editors: What motivated you to become Editor for $\mathrm{ABC}$ and what is most rewarding about being an $\mathrm{ABC}$ Editor? Which $\mathrm{ABC}$ feature do you like (best) and why?

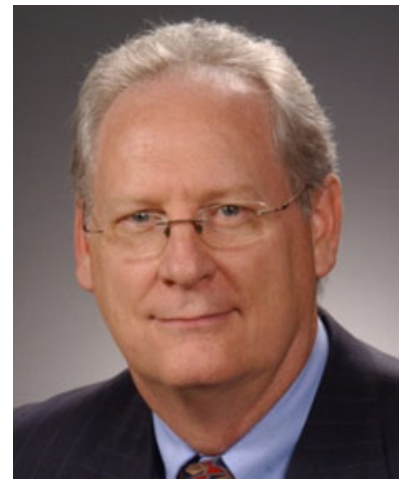

STEVE WISE: My motivation was based on my previous association with Fresenius, Journal of Analytical Chemistry, one of the original journals combined to create $\mathrm{ABC}$. I saw the creation of a new journal in analytical chemistry as an exciting challenge. The most rewarding aspects of being an editor of $\mathrm{ABC}$ are, for me, the personal interactions with the other editors and the editorial office staff of the journal, and of course the ever increasing quality and impact of the journal. 
KLAUS HEUMANN: My motivation to become an editor was that I much liked the idea of merging different European analytical chemistry journals to form a new internationally competent and distinguished analytical journal. The most rewarding aspect of being an editor is having direct access to scientific information and contacts with many different people all over the world. What is special about $\mathrm{ABC}$ is the great variety of different papers, for example original research papers, trend articles, critical reviews, feature articles, and the different columns.

GUENTER GAUGLITZ: When invited to become an editor of ABC I felt much honored, and my motivation was to contribute to the success of this journal as much as possible. I feel that it is most rewarding to be part of a very good team (consisting of the editorial office staff, the editors, and the advisory board members), and to follow the growing success of $\mathrm{ABC}$. Thus my plans for the future, beyond doing good research and assisting good people in obtaining their Ph.D, is to support ABC in its objective of increasing its visibility and impact. What I like best about $\mathrm{ABC}$ is the variety of the different $\mathrm{ABC}$ articles. To me this is the best contribution to bioanalytical research one can imagine. My favorite $\mathrm{ABC}$ feature is the critical reviews, because they critically discuss the "odds and ends" of different methods and provide a very good introduction to fields while covering peripheral areas and classical fields of (bio)analytical research (often enough overlapping with my own field).

ALDO RODA: To contribute to promoting analytical chemistry in Italy ...

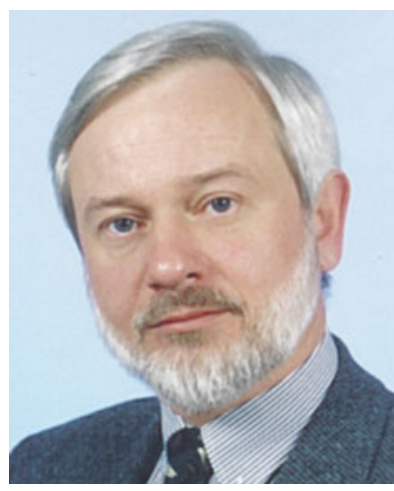

MACIEJ JAROSZ: My motivation to join the Board of Editors as Regional Editor Central Europe was continuation of the tradition of "Chemia Analityczna- Chemical Analysis" (merged with ABC in 2010). I must say I feel highly rewarded! What I like best about ABC? That it is open for all facets of target-oriented analytical chemistry.

ALFREDO SANZ-MEDEL: To me it was, first of all, the great challenge of contributing to promote a (bio) analytical chemistry journal which could rival the previously omnipresent Analytical Chemistry of the ACS. Then, of course, the great opportunity to promote analytical sciences of my country. Spain's analytical chemistry research is among the best in Europe (which is not so for many other scientific disciplines) and 10 years ago I realized the importance of $\mathrm{ABC}$ for this purpose. Finally, my personal scientific curiosity could be fulfilled, at least in part, by collaborating with my many renowned colleagues on the international editorial board (a real privilege for me) and the excellent professionals of the editorial office of $\mathrm{ABC}$.

SYLVIA DAUNERT: My motivations to become an ABC editor were the privilege of having first-hand exposure to state-of-the-art research and technology, to help in the advancement of science by being an integral part of its communication to the scientific community, and to affect, with my judgment and decisions (hopefully in a positive manner), what research should be in the forefront. I also love writing editorials on issues related to science and advances in discoveries of interest to the global scientific community. My favorite $\mathrm{ABC}$ feature is the research articles. My favorite one? It is impossible to single out one as there are simply too many, and they are in too many different disciplines of measurement science. ABC's contribution to (bio)analytical research is that it is a forum for communication of first-rate research in measurement science across disciplines. Our journal has given a voice to, and embraced work from, engineers, physicians, chemists, biochemists, environmental scientists, even art conservers, who have provided $\mathrm{ABC}$ with outstanding measurement publications. ABC started as a mostly European journal, but now it is truly a leading international journal.

KIYOKATSU JINNO: My motivation was the challenge of creating the top journal in the field of analytical chemistry. When I was invited to become one of the ABC editors, I had already been contributing in advisory and editorial boards of over 20 journals. From this experience I knew that an editor's role is important to the success of a journal. In addition, being an editor is the best position to know the most recent trends in a field. My favorite $A B C$ feature is the Trends articles - I find them a very interesting way of gaining a first insight into important research fields in analytical chemistry. Another feature I much enjoy is the column "ABCs of Teaching Analytical Chemistry" edited by C. Larive and R. Salzer, highlighting topics and developments in analytical chemistry education. Without education one cannot train researchers and scientists. This also affords continuous checks and evaluations of the performance of higher education programs in universities and graduate schools. In the EU such a system is currently being established. The series of short articles in ABC informs us of these important trends - and very few journals publish such material. $\mathrm{ABC}$ is, therefore, also extremely important in educational matters. 


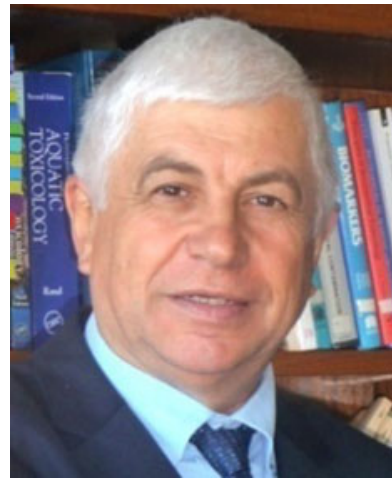

PHILIPPE GARRIGUES: At the beginning it was Springer and two scientific societies (SCF and GDCh), merging their own journals, Analusis and Fresenius' Journal of Analytical Chemistry, with the objective of creating THE European journal in analytical chemistry. This was a real challenge! To see the progress of the journal every year and to see the increasing number of submitted papers on high-quality research topics is the greatest reward one could ask for.

\section{Your forecast, where do you see $\mathrm{ABC}$ in 5/10 years from now?}

MACIEJ JAROSZ: Dreams? IF approximately 5, a truly excellent forefront paper in each issue, and the same excellent Springer team ...

PHILIPPE GARRIGUES: An IF over 5 and in the top five journals in analytical chemistry.

STEVE WISE: I see $\mathrm{ABC}$ as a premier journal for broad-scope analytical and bioanalytical chemistry similar to the journal Analytical Chemistry.

KLAUS HEUMANN: As one of the most popular analytical journals worldwide containing all the disciplines of the analytical sciences.

KIYOKATSU JINNO: Life sciences and environmental sciences are important areas of research in the 21 st century, and the bioanalytical contribution to these two sciences will increase with time. Following this trend, the importance of $\mathrm{ABC}$ with its high impact factor will also increase. In addition to the research-oriented content of $\mathrm{ABC}$ the impact of the educational column, especially those contributions focusing on higher education systems in natural sciences is very important.

GUENTER GAUGLITZ: A journal with a growing reputation and short lead times, which supports young scientists and has growing success in its efforts to cover peripheral fields of analysis.

ALFREDO SANZ-MEDEL: I see ABC achieving our initial objective of becoming the internationally leading
European based journal, publishing innovative research in analytical chemistry. Of course, to get there we should continue being more demanding with regard to the originality, novelty, and relevance of the work published in the journal. For the nearer future, my impression is that the focus of $\mathrm{ABC}$ will continue to move further toward life-science analysis (e.g. brain-related investigations) and toward multidisciplinary/interdisciplinary research.

SYLVIA DAUNERT: I see ABC as a leading journal in all fields of measurement science, not just analytical chemistry. I expect that if we continue being as selective as we are with regard to the quality of the work published, improve our website and features constantly, and re-invent our layouts and contents periodically, we will surpass all other "analytical" journals, and will catch-up with Analytical Chemistry, which is currently the \#1 journal in measurement science, well ahead of the pack.

And now for the finale a simple question: $\mathrm{ABC}$ is ...

MACIEJ JAROSZ: ... challenging!

GUENTER GAUGLITZ: ... a successful leading journal in analysis, covering a wide range of different fields, providing trends, critical reviews, rapid communications, and becoming a standard in the publishing analytical results.

SYLVIA DAUNERT: .... a journal at the forefront of science, more specifically in the broad area of measurement science. Every single discipline of science and technology must measure data and study molecules in a quantitative, reproducible, and accurate manner, to advance discovery. Thus, measurement science is paramount in all fields and disciplines, and our journal addresses and includes the work of scientists from a variety of fields who perform measurements and develop new measurement methods, techniques, and instruments.

KLAUS HEUMANN: ... what I would miss immensely whenever I retire as Editor and where I am always busy with manuscripts, not only on rainy days.

PHILIPPE GARRIGUES: ...the best analytical chemistry journal in the world!

With this resume I would like to thank you for your answers, for sharing your ideas and your views. And, last but not least, for making $\mathrm{ABC}$ such a success story! 